\title{
USING ERP IN CURRICULUM INTEGRATION: A CASE STUDY
}

\author{
Roger L. Hayen, Central Michigan University, roger.hayen@cmich.edu \\ Daniel E. Vetter, Central Michigan University, vette1de@cmich.edu \\ Zhenyu Huang, Central Michigan University, huang1z@cmich.edu
}

\begin{abstract}
The business college at the authors' university embarked on a revised bachelor of science in business administration (BSBA) degree. The revisions to the degree focus on the common body of knowledge (CBK) courses that are required of all BSBA degree students. Primary goals of the revisions are enhanced teamwork activities, improved Enterprise Resource Planning (ERP) software knowledge, and increased integration of concepts among functional area courses. Two surveys at different times are administered to examine the impact of the program on teamwork and integration. The results show progress in achieving these goals for this revised degree program.
\end{abstract}

Keywords: Integrated core courses, cohort course team experiences, ERP software, SAP system

\section{INTRODUCTION}

The College of Business Administration (CBA) at the authors' university embarked on a revised bachelor of science in business administration (BSBA) degree. The revisions to the degree focus on the common body of knowledge (CBK) courses that are required of all BSBA degree students. Primary revisions to the BSBA are concerned with increased team work activities and the integration of concepts among courses. The curriculum effort centers on three essential goals:

1. Enhance teamwork activities,

2. Expand ERP system knowledge to all BSBA degree students, and

3. Integrate learning outcomes among functional business areas using ERP systems and a business decision making simulation.

This research reports on the design of the new BSBA degree program and the outcomes of an ERP systems integrated curriculum after its first year of implementation. First, the new revised curriculum is presented. Second, the results of two student surveys are presented and summarized. Last, the results are interpreted as an evaluation of achieving the expected primary goals.

\section{OTHER EFFORTS}

The concept of integrating business concepts among the various functional area courses of a BSBA degree program is not new. A variety of approaches have been used including a process approach [8], a teamteaching approach [7], a competency approach [3], and infrastructure issues [6]. A number of efforts have been used for including Enterprise Resource Planning (ERP) systems in required core courses for a BSBA degree [2], [4]. Overall, these undertakings have used ERP systems as a mechanism to demonstrate integrated business processes, usually in a single course, rather than as a vehicle for linking the functional area courses and their concepts with those integrated processes. Several prior efforts with ERP systems have focused primarily on introducing ERP software into business curriculums to demonstrate its use and the integration of business processes [1], [5]. That is, these integration efforts are primarily to just bring in ERP systems into the business curriculum and not as a primary force in the actual integration of the core courses within that curriculum. This curriculum integration effort is different from these prior efforts in that it relies on ERP systems as a key aspect in delivering integrated business processes together with an emphasis on enhanced teamwork activities. It includes a new required course added to the curriculum to address integrated business processes through ERP systems.

\section{REVISED BSBA INTEGRATED CORE}

Primary revisions to the BSBA for the integrated core are concerned with increasing team work activities and merging functional area concepts among courses. The integration is achieved by offering two blocks of courses - one the sophomore year and the other in the junior year (Figure 1). The sophomore block consists of ACC 255 - Managerial Accounting and Decision Making and BIS 255 - Information Systems. The junior block consists of BUS 301 - Integrated Business Experience, FIN 302 - Integrated Financial Analysis, MGT 303 - Integrated Supply Chain Management, and MKT 304 - Integrated Marketing Management. During a block, the students attend the same courses in a cohort configuration. A student may be in a different block for the sophomore and 
junior years, but they take both blocks under a cohort composition. Within each block, the students are organized in the same teams. That is, students are in the same teams in ACC 255 and BIS 255, and similarly for the junior year. As a means of implementing the integration between these core courses, exploratory cases in BIS 255 were selected that would support the concepts and ideas included in ACC 255. The BIS 255 course included a module in ERP software used to both examine this type of business software and provide students with a better understanding of the integration of business process by exploring transaction processing in today's businesses. This learning module in BIS 255 is designed to support the use of enterprise software in examine accounting transaction data in ACC 255.

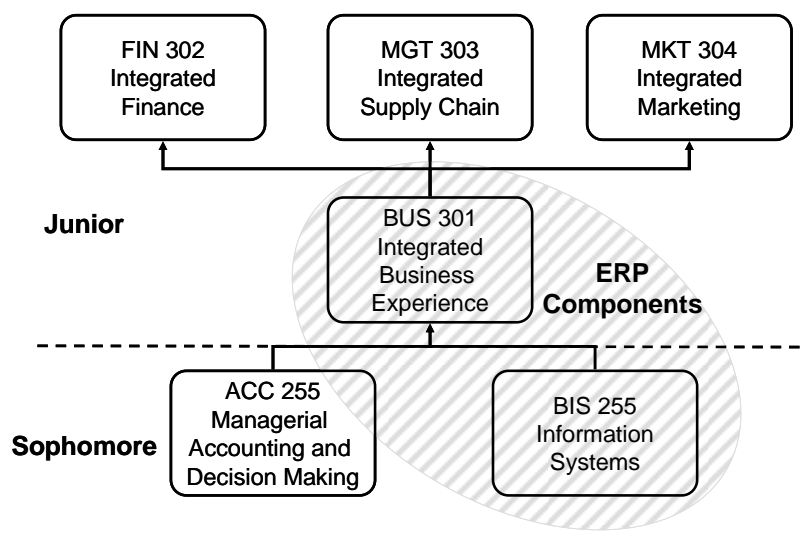

Figure 1. Integrated Core Courses Design

BUS 301 - Integrated Business Experience (Figure 1) is an entirely new core, required course included in the curriculum to focus on the integration of business concepts and their application. This course is divided in to two primary modules. The first module focuses on the business processes of the customer order to cash cycle. The SAP Enterprise Software is the ERP system used to examine these processes in a realworld business environment. This ERP module explores business processes at the detailed transaction level. The second module of this course is concerned with business decision making at a strategic level. In the BUS 301 course, this is implemented using the Marketplace Simulation. This simulation present summarized historical data and an environment for making future decision in a competitive situation with other teams within the same section of a course. For BUS 301, the SAP ERP and the Marketplace Simulation are linked conceptually within the course. However, there is no hard data that passes from SAP to the Marketplace Simulation and visa versa. For the new integrated core, this conceptual interrelationship was determined to be appropriate in the design of the course by faculty. Recall that students are concurrently enrolled in the other three 300-level courses. As they learn about the business processes in those core courses, they experience the integration in BUS 301. Students are asked and expected to apply many of the concepts of the functional area core courses in the analysis and decision making that takes place in the BUS 301 course. With this design, some functional concepts have a strong connection whereas others are more loosely connected. Were the students satisfied with this new integrated CBK experience? This study was undertaken specifically to address to this issue.

\section{PARTICIPANTS}

Two different surveys were conducted to obtain student reactions to the newly designed program (Table 1). Students were surveyed in BIS 255 at the sophomore level to obtain their response to organization and content elements of both the ACC 255 and BIS 255 courses. Second, students were surveyed in BUS 301 at the junior level to obtain their response to the organization and content elements of that course relative to the other three core courses taken concurrently by these students. Although not a complete match, the students surveyed in BIS 255 (sophomore level) were the same students surveyed the very next semester in BUS 301 (junior level). As detailed surveys, the BIS 255 and BUS 301 surveys contain a focus on business process integration using ERP software and teamwork activities.

Table 1: Survey Instruments

\begin{tabular}{|c|c|c|}
\hline Survey & Description & Participants \\
\hline A & Detail BIS 255 sophomore level & 93 \\
\hline B & Detail BUS 301 junior level & 113 \\
\hline
\end{tabular}

For all surveys, these students were enrolled in the courses during the semesters in which the surveys were administered. The samples consisted of $70 \%$ male and $30 \%$ female students and are consistent across surveys for both semesters $(\chi, \mathrm{p}=0.9572)$. Similar consistency was obtained for different student majors.

\section{SURVEY RESULTS}

The survey results are examined in two parts. First, the detailed, micro results for the junior semester are explored. Second, teamwork results are compared 
between the sophomore and junior semester integrated cohort groups. For both the sophomore and junior semester detailed results, the results for only the key items that focus on course integration, ERP deployment, and teamwork are included in this analysis. Although the other survey questions provide additional insight into course activities, they are considered to be beyond the scope of this analysis.

\section{Detailed Sophomore Survey Outcomes}

The detailed survey was conducted to assess the value of delivering the cohort BIS 255 and ACC 255 courses. This survey consists of 19 questions including two demographic questions for a student's gender and major. Of those 19 questions, results are reported here are for the nine key questions included in the survey (Table 2). Although the other questions are interesting for future course development, the nine key questions provide the most insight into the primary issue of the integrated core including enhancing teamwork experiences. For most questions, participants were asked to respond to questions using a 7-point Likert scale, where 7 indicates "extremely satisfied” or "strongly agree," 4 “don't know/no opinion" and 1 "extremely dissatisfied" or "strongly disagree." The survey also contained the demographic questions and two questions asked participants to indicate the relative quantity of an item. The last four items were open-ended questions, which focus on important benefits of these cohort courses and any additional thoughts or comments that students might have. Excluding the demographic data, the survey's key questions can be grouped into the three general categories. The dimensions of these categories

are:

1. Understanding gained through inclusion of the of SAP R/3 Enterprise Software component as an ERP course component (ERP).

2. Support for integration of ACC 255 concepts and ideas by the BIS 255 course (Int).

3. Extent of team interactions (Team).

Table 2 is a list of the nine key questions with these general category dimensions, where these dimensions are useful in providing a summarized overview of student responses in these categories. To minimize response bias, questions 7 , and 8 were negatively stated. For analysis purposes, these questions were reverse-coded to facilitate an easier comparison to the other responses. These items are stated in reversecoded form in Table 2. The general category responses are an average of the responses to the individual item questions in each category.

Tables 3 and 4 present the average response for each of the key questions 1 through 8 . While many of the questions have an average response of four or more, some do not. Questions 2, 3, and 4 have responses with an average less than four. Although these are close to that average, they indicate areas where additional attention needs to be directed in future semesters to enhance the ERP and integration aspects of these courses. Table 3 summarizes respondent's perception about their understanding of the SAP R/3 software course content related to ERP system concepts and integration among courses. Whereas the ERP course component did support learning of ERP and its integrated business processes, the results indicate that additional focus needs to be provided for students to help them bridge an apparent gap between the textbook ERP concepts and the hands-on exercises in the SAP R/3 software. Table 4 presents the results for the satisfaction of the team outcome measures. Overall, the teamwork outcomes provide a positive indication the teamwork component of the sophomore integrated cohort core courses is successful. This is not to say that improvements cannot be made. However, the data suggest the new design for the cohort core resulted in a strong teamwork experience, as was desired as a goal in the design of the new BSBA.

In the BIS 255 course, teams were organized with sizes of 3 and 4 members. The target was a team size of 3; however, differing class sizes resulted in some teams with additional members for an average team size of 3.2. Question 9 asked students to indicate in one of three categories, if the team size was just right, should be increased, or should be decreased. The team size results are most interesting. Eighty percent of the students responded the average team size of 3.2 was too large. This indicates most student would have preferred a team size of 2 . That is, they preferred to work with only one other student. Clearly, this result is a surprise and represents an unrealistic team size. This appears to be an issue for which students need to gain a better understanding 
Table 2: BIS 255 Course Assessment Key Questions

\begin{tabular}{|c|c|c|c|c|c|}
\hline $\begin{array}{l}\text { Key } \\
\text { Item }\end{array}$ & \multicolumn{4}{|c|}{ Questions } & Category \\
\hline 1 & \multicolumn{4}{|c|}{$\begin{array}{l}\text { Which of the following best describes your overall level of satisfaction with the SAP R/3 Software assignment you } \\
\text { completed in BIS } 255 \text { when learning about the SAP R/3 System and integrated business processes? }\end{array}$} & ERP \\
\hline 2 & \multicolumn{4}{|c|}{$\begin{array}{l}\text { The SAP R/3 software assignment helped me better understand the issues, concepts, and ideas presented in the readings } \\
\text { in BIS } 255 \text { that were assigned on enterprise resource planning systems or enterprise software. }\end{array}$} & ERP \\
\hline 3 & \multicolumn{4}{|c|}{$\begin{array}{l}\text { The SAP R/ } 3 \text { software assignments in BIS } 255 \text { helped me better understand the concepts and ideas presented in the } \\
\text { readings and assignments in ACC } 255 \text { that were related to business transactions, problem solving, and their application } \\
\text { in business. }\end{array}$} & Int \\
\hline 4 & \multicolumn{4}{|c|}{$\begin{array}{l}\text { The SAP software, Excel, and Access case project assignments in BIS } 255 \text { helped me to better understand the } \\
\text { concepts and ideas in ACC } 255 .\end{array}$} & Intt \\
\hline 5 & \multicolumn{4}{|c|}{$\begin{array}{l}\text { Overall, the teamwork in both ACC } 255 \text { and BIS } 255 \text { helped me to improve my communication and other skills in } \\
\text { working as a team in solving business problems. }\end{array}$} & Team \\
\hline 6 & \multicolumn{4}{|c|}{ Our team worked together effectively on the course projects. } & Team \\
\hline 7 & \multicolumn{4}{|c|}{$\begin{array}{l}\text { I would prefer that we work in the same teams in ACC } 255 \text { and BIS 255, rather than being in different teams in both } \\
\text { courses.* }\end{array}$} & Team \\
\hline 8 & \multicolumn{4}{|c|}{ Completing the case project assignments as a group is better than working on them individually.* } & Team \\
\hline 9 & \multicolumn{4}{|c|}{ What is your opinion about the size of the teams used in BIS 255 (that is, the number of team members)? } & Team \\
\hline \multicolumn{6}{|c|}{ Table 3: Impact of ERP and Integration } \\
\hline & $\begin{array}{c}\text { Item } \\
\text { (Survey question number) }\end{array}$ & Mean & StdDev & $\begin{array}{l}\text { \%Satisfied, } \\
\text { \% Agree }\end{array}$ & $\begin{array}{l}\text { satisfied, } \\
\text { isagree }\end{array}$ \\
\hline \multicolumn{2}{|c|}{$\begin{array}{l}\text { Which of the following best describes your overall level of satisfaction } \\
\text { with the SAP R/3 Software assignment you completed in BIS } 255 \text { when } \\
\text { learning about the SAP R/3 System and integrated business processes? } \\
\text { (1) }\end{array}$} & 4.23 & 1.54 & $47 \%$ & $3 \%$ \\
\hline \multicolumn{2}{|c|}{$\begin{array}{l}\text { The SAP R/3 software assignment helped me better understand the issues, } \\
\text { concepts, and ideas presented in the readings in BIS } 255 \text { that were } \\
\text { assigned on enterprise resource planning systems or enterprise software. } \\
\text { (2) }\end{array}$} & 3.85 & 1.73 & $39 \%$ & $46 \%$ \\
\hline \multicolumn{2}{|c|}{$\begin{array}{l}\text { The SAP R/3 software assignments in BIS } 255 \text { helped me better } \\
\text { understand the concepts and ideas presented in the readings and } \\
\text { assignments in ACC } 255 \text { that were related to business transactions, } \\
\text { problem solving, and their application in business. (3) }\end{array}$} & 3.44 & 1.66 & $28 \%$ & $2 \%$ \\
\hline \multicolumn{2}{|c|}{$\begin{array}{l}\text { The SAP software, Excel, and Access case project assignments in BIS } \\
255 \text { helped me to better understand the concepts and ideas in ACC } 255 . \\
\text { (4) }\end{array}$} & 3.84 & 1.85 & $43 \%$ & $3 \%$ \\
\hline
\end{tabular}

Table 4: Team Outcome Measures

\begin{tabular}{|c|c|c|c|c|}
\hline $\begin{array}{c}\text { Item } \\
\text { (Survey question number) }\end{array}$ & Mean & Std Dev & $\begin{array}{l}\text { \%Satisfied, } \\
\text { \% Agree }\end{array}$ & $\begin{array}{l}\text { \% Dissatisfied, } \\
\text { \% Disagree }\end{array}$ \\
\hline $\begin{array}{l}\text { Overall, the teamwork in both ACC } 255 \text { and BIS } 255 \text { helped me to } \\
\text { improve my communication and other skills in working as a team in } \\
\text { solving business problems. (5) }\end{array}$ & 5.26 & 1.54 & $78 \%$ & $13 \%$ \\
\hline Our team worked together effectively on the course projects. (6) & 5.63 & 1.57 & $84 \%$ & $13 \%$ \\
\hline $\begin{array}{l}\text { I would prefer that we work in the same teams in ACC } 255 \text { and BIS 255, } \\
\text { rather than being in different teams in both courses. (7)* }\end{array}$ & 4.58 & 2.05 & $53 \%$ & $43 \%$ \\
\hline $\begin{array}{l}\text { Completing the case project assignments as a group is better than } \\
\text { working on them individually. (8)* }\end{array}$ & 5.51 & 1.83 & $76 \%$ & $20 \%$ \\
\hline
\end{tabular}

* Indicates a reverse-coded question

\section{Detailed Junior Survey Outcomes}

The survey was conducted to assess the value of delivering the largest concurrent set of courses for the integrated core cohort. Recall, this is the four courses of BUS 301, FIN 302, MGT 303, and MKT 304. At this junior level, a different detailed survey was completed. This survey consists of 20 questions includ- ing two demographic questions for a student's gender and major. Of those 20 questions, results are reported here are for the nine key questions included in the survey (Table 5). Although the other questions are interesting, the nine key questions provide the most insight into the primary issue of the integrated core including enhancing teamwork experiences. Following the design of the sophomore survey, par- 
ticipants were asked to respond to questions using the same 7-point Likert scale. The survey also contained the demographic and open-ended questions Excluding the demographic data, the survey's key questions are grouped into two general categories of integration (Int) and teamwork (Team). A separate category for ERP is not considered here, because the ERP content is intertwined with the overall integration content (Int). Hence, achieving integration also is an indicator for the deployment of ERP software at the junior level.

Tables 6 and 7 present the average response for each of the key questions 1 through 8 . All of the have an average response of four or more. Clearly, questions 2 concerning the Marketplace Simulation impact on integrated decision making stands out with the largest bearing among the integration initiatives. Table 6 reviews respondents' perceptions of the support of the four CBK courses. From these results, the role of the Marketplace Simulation (Item 2) in understanding business decision making and its integrated affects stands out as the single most prominent learning activity (82 percent agree). On the other hand, taking the four courses concurrently (Item1) has the lowest score (58\% agree). So, while this is the lowest scoring item, it still is a positive factor in contributing to integration. However, additional experience with these four CBK courses is still expected to increase student understanding of integration. Table 7 presents the results for the satisfaction of the team outcome measures. Overall, the teamwork outcomes provide a positive indication the teamwork component of the junior cohort core courses is also successful. Again, the data support a strong teamwork experience in the new cohort core.

In the BUS 301 course, teams were organized with sizes of 6 and 7 members. The target was a team size of 6; again, differing class sizes resulted in some teams with additional members for an average team size of 6.3. Question 9 asked students to indicate in one of the same three categories if the team size was just right, should be increased, or should be decreased. A target team size of 6 was used because of the student top management organization of the Marketplace Simulation. This simulation is designed with six "top management" positions. For a smaller team size, some students are required to take the responsibilities of more that one position. Some of the positions are more demanding and have more responsibility and work effort required than others. It is possible for a team to function well in the simulation with only 4 team members. On the other hand, the number of team members needs to be balanced with the number of teams competing in the simulation in any one section of a course. Based on the survey results and the Marketplace Simulation, a target team size of 5 should work much better, with an absolute maximum of 6 and the possibility to have some smaller team sizes of 4 .

\section{Teamwork Results}

The teamwork questions (Items 5 through 9) on both the sophomore and junior detailed questionnaire are very similar. The difference between the items on the two questionnaires is the references to the courses in which the students are enrolled each of the two semesters. These questions permit the comparison of student perceptions between the two semester experiences. Items 5 through 8 use the 7-point Likert scale, whereas Item 9 is the team size question with three alternatives. Table 8 displays the comparisons between Items 5 through 8 . These results indicate similar experiences for both semesters. Students perceived that teamwork improved team communication skills (Item 5) and they prefer working in the same teams across the courses taken during a semester, rather than working in a different team for each course (Item 7). Conversely, the data indicate essentially no difference in student perception in the extent of working effectively as a team (Item 6) and completing all assignments as a group is better than working on them individually (Item 8). Although the results for Items 5 and 7 are positive, they are not as strong for the junior cohort as they are for the sophomore cohort. These data suggest that the two course sophomore cohort produced a better teamwork environment than that of the four course junior cohort. Therefore, more attention should be directed to team activities for the junior level cohort. That attention should include the needs of the Marketplace Simulation in the BUS 301 course as well as those for the other three functional area courses.

For the questions, Item 9 addresses the issue of the team size. The data reveal there is a difference between the student perceptions of team size across the two semesters $(\chi, \mathrm{p}=0.0002)$. For the junior cohort, a significantly greater portion of the student indicated the team size was about right. Essentially no students ( 2 percent) indicated the team size (average size $=$ 6.3) should be increased. This further supports using smaller teams with the Marketplace Simulation in BUS 301. 
Table 5: BUS 301 Course Assessment Key Questions

\begin{tabular}{|c|c|c|c|c|}
\hline $\begin{array}{l}\text { Key } \\
\text { Item }\end{array}$ & \multicolumn{3}{|l|}{ Questions } & Category \\
\hline 1 & \multicolumn{3}{|c|}{$\begin{array}{l}\text { Taking the marketing (MKT 304), finance (FIN 302), and management (MGT 303) courses concurrently } \\
\text { with BUS } 301 \text { helped me better understand the integration of the concepts and ideas of the functional areas } \\
\text { of business. }\end{array}$} & S \\
\hline 2 & \multicolumn{3}{|c|}{$\begin{array}{l}\text { The Marketplace Simulation helped me to better understand the relationships of business decision making } \\
\text { among marketing, finance, and management. }\end{array}$} & Int \\
\hline 3 & \multicolumn{3}{|c|}{$\begin{array}{l}\text { The SAP R/3 software assignments helped me understand how integrated business transaction processing } \\
\text { works to support the actions resulting from business decision making. }\end{array}$} & Int \\
\hline 4 & \multicolumn{3}{|c|}{$\begin{array}{l}\text { The SAP R/3 Software and Marketplace Simulation assignments helped me to better understand integrated } \\
\text { business processes and business decision making. }\end{array}$} & Int \\
\hline 5 & \multicolumn{3}{|c|}{$\begin{array}{l}\text { Overall, the teamwork in all four common body of knowledge (CBK) courses helped me improve my } \\
\text { communication and other skills in working as a team in solving business problems. }\end{array}$} & Team \\
\hline 6 & \multicolumn{3}{|c|}{ Our team worked together effectively on all assignments in all four CBK courses. } & Team \\
\hline 7 & \multicolumn{3}{|c|}{$\begin{array}{l}\text { I would prefer that we work in the same teams in all of the CBK courses, rather than being in different } \\
\text { teams in each course.* }\end{array}$} & Team \\
\hline 8 & \multicolumn{3}{|c|}{ Completing all assignments as a group is better than working on them individually.* } & Team \\
\hline 9 & \multicolumn{3}{|c|}{ What is your opinion about the size of the teams used in BUS 301 (that is, the number of team members)? } & Team \\
\hline \multicolumn{5}{|c|}{ Table 6: Impact of ERP and Integration } \\
\hline & $\begin{array}{c}\text { Item } \\
\text { (Survey question number) }\end{array}$ & Mean & $\begin{array}{l}\text { \%Satisfied, } \\
\text { \% Agree }\end{array}$ & $\begin{array}{l}\text { \% Dissatisfied, } \\
\text { \% Disagree }\end{array}$ \\
\hline \multicolumn{2}{|c|}{$\begin{array}{l}\text { Taking the marketing (MKT 304), finance (FIN 302), and management (MGT } \\
\text { 303) courses concurrently with BUS } 301 \text { helped me better understand the } \\
\text { integration of the concepts and ideas of the functional areas of business. (1) }\end{array}$} & 4.17 & $58 \%$ & $40 \%$ \\
\hline \multicolumn{2}{|c|}{$\begin{array}{l}\text { The Marketplace Simulation helped me to better understand the relationships of } \\
\text { business decision making among marketing, finance, and management. (2) }\end{array}$} & 5.11 & $82 \%$ & $17 \%$ \\
\hline \multicolumn{2}{|c|}{$\begin{array}{l}\text { The SAP R/3 software assignments helped me understand how integrated } \\
\text { business transaction processing works to support the actions resulting from } \\
\text { business decision making. (3) }\end{array}$} & 4.66 & $67 \%$ & $24 \%$ \\
\hline \multicolumn{2}{|c|}{$\begin{array}{l}\text { The SAP R/3 Software and Marketplace Simulation assignments helped me to } \\
\text { better understand integrated business processes and business decision making. } \\
\text { (4) }\end{array}$} & 4.81 & $72 \%$ & $23 \%$ \\
\hline
\end{tabular}

Table 7: Team Outcome Measures

\begin{tabular}{|c|c|c|c|c|}
\hline $\begin{array}{c}\text { Item } \\
\text { (Survey question number) }\end{array}$ & Mean & Std Dev & $\begin{array}{l}\text { \%Satisfied, } \\
\text { \% Agree }\end{array}$ & $\begin{array}{l}\text { \% Dissatisfied, } \\
\text { \% Disagree }\end{array}$ \\
\hline $\begin{array}{l}\text { Overall, the teamwork in all four common body of knowledge (CBK) courses } \\
\text { helped me improve my communication and other skills in working as a team in } \\
\text { solving business problems. (5) }\end{array}$ & 4.70 & 1.79 & $64 \%$ & $26 \%$ \\
\hline $\begin{array}{l}\text { Our team worked together effectively on all assignments in all four CBK } \\
\text { courses. (6) }\end{array}$ & 4.88 & 1.87 & $60 \%$ & $24 \%$ \\
\hline $\begin{array}{l}\text { I would prefer that we work in the same teams in all of the CBK courses, } \\
\text { rather than being in different teams in each course. }(7)^{*}\end{array}$ & 4.50 & 2.10 & $51 \%$ & $33 \%$ \\
\hline $\begin{array}{l}\text { Completing all assignments as a group is better than working on them } \\
\text { individually. (8)* }\end{array}$ & 4.74 & 1.96 & $61 \%$ & $27 \%$ \\
\hline
\end{tabular}

Table 8. Teamwork Significance Between Sophomore and Junior Groups

\begin{tabular}{|l|l|l|}
\multicolumn{1}{c|}{\begin{tabular}{c}
\multicolumn{1}{c|}{ Item } \\
(Survey question number)
\end{tabular}} & $\begin{array}{c}\text { Significant at } \\
\text { 0.05 p-Value }\end{array}$ \\
\hline $\begin{array}{l}\text { Overall, the teamwork in the CBK courses helped me improve my communication and other } \\
\text { skills in working as a team in solving business problems. (5) }\end{array}$ & 0.2889 & Yes \\
\hline Our team worked together effectively on all assignments in our CBK courses. (6) & 0.0087 & No \\
\hline $\begin{array}{l}\text { I would prefer that we work in the same teams in the BSBA core courses, rather than being } \\
\text { in different teams in each course. (7)* }\end{array}$ & 0.8127 & Yes \\
\hline Completing all assignments as a group is better than working on them individually. (8)* & 0.0162 & No \\
\hline
\end{tabular}




\section{SUMMARY AND CONCLUSION}

This research investigated the new integrated cohort BSBA degree program. Overall, the deployment of ERP software contributes to the integration of the concepts studied across the functional area courses. As integrated software, student gain knowledge with integrated business processes through the customer order to cash cycle. This integration has an increased impact in the junior level experience with the four core cohort courses. So, the results indicate the effect of integration begins in the sophomore experience and build to a higher level in the junior experience. The Marketplace Simulation provides a substantial understanding of business decision making and the functional area concepts of junior level cohort courses. Clearly, the SAP R/3 (ERP) Software and Marketplace Simulation provide students with a better understanding of integrated business processes. Further attention to these components of the cohort core should yield even additional gains in this integration.

The results strongly suggest an enhancement of teamwork activities is achieved with the new BSBA program. This is especially the situation for team communication and a preference to work in teams rather than to work individually. Regarding team size, some of the results remain unexplained. That is, a team size of 3 being too large at the sophomore level. However, the data for the junior level make more sense with a team size of 6 or 7 as too large. Weighing these student perceptions and the structure of the Marketplace Simulation, a target team size of 5 appears to be most appropriate for the junior experience. This is a change that should be made and then monitored in future semesters.

So, overall, the new integrated cohort core BSBA degree program appears to be achieving its objectives, while some issues require attention to improve the student experience in this program. This revised BSBA degree required further examination in future semesters to determine it longer term results. Others are encouraged to conduct similar studies on their BSBA degree programs and to share their lessons learned.

\section{REFERENCES}

1. Antonucci, Y. L., Corbitt, G., Stewart, G. and Harris, A. L. (2004). Enterprise Systems Education: Where Are We/ Where Are We Going? Journal of Information Systems Education, 15(3), 227-234.

2. Cannon, D.M., Klein, H. A., Koste, L. L., and Magal, S. R. (2004). Curriculum Integration Using Enterprise Resource Planning: An Integrative Case Approach, Journal of Education for Business, 80(2), 93-102.

3. Chyung, S. Y., Stepich, D., and Cox, D. (2006). Building a Competency-Base Curriculum Architecture to Educate $21^{\text {st }}$ Century Business Practitioners, Journal of Education for Business, 81(6), 307-311.

4. Hawking, P., Ramp, A. and Shackleton, P. (2001). IS '97 model curriculum and ERP systems, Business Process Management Journal, 7(3), 225-233.

5. Hayen, R. L., J. J. Cappel, and M. C. Holmes (2000). A Framework of SAP R/3 Enterprise Software Instruction, Journal of Computer Information Systems, 40(2), 79-85.

6. Pharr, S. W. (2000). Foundational Considerations for Establishing and Integrated Business Common Core Curriculum, Journal of Education for Business, 76(1), 20-23.

7. Smith-Ducoffe, S. J., Tromley, C. L., and Tucker, M. (2006). Interdisciplinary, TeamTaught, Undergraduate Business Courses: The Impact of Integration, Journal of Management Education, 30(2), 276-294.

8. Walker, K. B. and Ainsworth, P. L. (2001). Developing a Process Approach in the Business Core Curriculum, Issues in Accounting Education, 16(1). 41-66. 